\title{
Using Health Belief Model, TriRisk Model, and Fatalism to predict COVID-19 Social Distancing Compliance Behavior \\ Sugato Lahiry ${ }^{1 *}$ \\ Rita Karmakar ${ }^{2}$ \\ Swathy Parameswaran ${ }^{3}$
}

\begin{abstract}
Amid a raging COVID-19 pandemic, governments everywhere need to deploy more targeted strategies to make social distancing effective and reduce human to human transmission of the virus.

357 Participants across India participated in the study. The age range of participants were 15- 78 years $(M=47.64, S D=14.46), 41.5 \%$ of whom were men and $58.5 \%$ were women. Multi-item and single-item scales were used to assess risk perceptions, basic components of the health belief model, fatalism, and social distancing compliance behavior.

The results revealed that experiential risk perception was the strongest predictor followed by perceived barriers and gender. Deliberative risk perception and affective risk perception were significantly positively correlated with compliance behavior, though neither turned out to be statistically significant predictors of compliance behavior. Experiential risk perception mediated the path between cognitive risk assessment and compliance behavior.

The study has implications in designing lockdown/social distancing compliance strategies.

Keywords: Social Distancing Compliance Behavior, Fatalism, Health belief model, COVID-19, Risk perception, Predictive Model, Mediation Analysis.
\end{abstract}

\section{Introduction}

With a high reproduction number, mean $\mathrm{R}_{0}$ of 3.28 across China (Liu et al., 2020), SARS-CoV2 was a ticking pandemic time bomb from the time it first emerged in December, 2019 in Wuhan, China. WHO declared COVID-19 to be a pandemic on March 11, 2020, and in just about 6 months, on September 18, globally the number of COVID-19 cases surpassed 30 million, according to figures released by Johns Hopkins University.

\footnotetext{
${ }^{1}$ Sugato Lahiry is President, TTMS-PeopleProfit, India. sugato@peopleprofit.in

2 Rita Karmakar is Assistant Professor, Amity Institute of Psychology \& Allied Sciences, Amity University Kolkata

${ }^{3}$ Swathy Parameswaran is a Ph.D. scholar at Indian Institute of Technology, Chennai, India and is a Research Associate at TTMS-PeopleProfit.

Funding: This research was conducted under the aegis of PeopleProfit Social Research Initiative (SRI) and no external funding was received.

Competing interests: The authors declare that no competing interests exist.
} 
While lockdown and social distancing emerged as the global strategy to fight the spread of Covid-19, the success of such measures in slowing down or stopping the spread ultimately depends on people's response to such preventive measures. The ability to predict compliance behavior of individuals in response to the Covid-19 crisis could pave the way for designing better communication and intervention strategies to save lives and improve the returns on the economic costs of lockdown.

In planning research on health behavior change strategies, the researcher is faced with a profusion of theoretical frameworks that seek to explain the emergence of self-preventive health behavior. Summarised somewhat differently by different authors (Biddle \& Nigg, 2000; Murray-Johnson et al., 2005;Noar \& Zimmerman, 2005;Epton et al., 2013), these include: the Behavioral Decisions Theory (Edwards, 1961), Protection Motivation Theory (Maddux \& Rogers, 1983), Health Belief Model (Becker, 1974; Rosenstock, 1974), Theory of Reasoned Action (Ajzen and Fishbein, 1980), Theory of Planned Behavior (Ajzen \& Madden, 1986), an Integrated Model of Behavior Change (Ajzen \& Fishbein, 2000), Social Cognitive Theory (Bandura, 1986), Transtheoretical Model (Prochaska \& DiClemente, 1983), Extended Parallel Process Model, which attempts to integrate the large array of the Fear Appeal Theories (Witte, 1994), among others. One theory that stands out in this ensemble cast, by virtue of the sheer amount of attention it has received from researchers, is the Health Belief Model.

Since Hochbaum first reported in 1958 that 'perceived susceptibility' to TB, along with other health beliefs, differentiated between those who went for chest X-ray screening and those who did not (Abraham \& Sheeran 2005), an extensive and impressive body of research has built upon the role of Risk Perception and other components of the Health Belief Model. Over the last 50 years, the Health Belief Model has been "one of the most widely applied conceptual model in the health behavior domain for both explaining and designing 
interventions related to health behavior change" (Skinner et al., 2015). The focus on the Health Belief Model and the role of perceived risk within it continues to this day.

The Health Belief Model (HBM) was developed in the 1950s, in response to the challenge faced by the US public health service in getting people to opt for early detection tests or other preventive steps for asymptomatic diseases (Rosenstock, 1974). In its original form HBM postulated a set of five factors that were needed to propel people to action. 1) Perceived susceptibility to a disease, 2) Perceived severity of the disease, 3) Perceived benefit in taking the recommended preventive action; 4) Low perceived barrier (e.g., cost, inconvenience, pain, embarrassment, etc.) to taking the recommended preventive action; 5) A trigger (e.g., campaigns by health authorities) to instigate the preventive action.

The model evolved and expanded over time to include other risk perception elements. The original construct of perceived susceptibility comprised a cognitive estimate by the respondents of their likelihood of contracting a disease. Slovic et al., (2005) pointed out that risk is perceived in two main ways: A) as a cognitive "analysis" of the probability judgment of danger and B) as an affective element he called 'affect heuristic'; and that decision making involves the integration of "both modes of thought". Within the affective element of risk perception, Loewenstein et al. (2001) made a distinction between "anticipatory" emotions (e.g., fear or anxiety) about the possibility of harm, and "anticipated" emotions (e.g. regret or guilt) about the "expected consequences of the decision". Brewer et al., (2007) reported that in addition to anxiety and regret, vaccination behavior increased with the increasing 'feeling at risk' and as such it could be a better predictor of self-protective behaviors such as vaccination than cognitive judgment of probability of risk. The initial conceptualization and operationalization of the risk perception construct, which was limited to only its analytical, 
cognitive element to the exclusion of the affective/experiential elements is one of the reasons that many meta-analytic studies, ( e.g., Brewer et al., 2007; Floyd et al., 2000; Gerrard et al., 1996) found a significant but only modest association between perceived risk, intentions and behavior (Epton et al., 2013). In the same meta-analytic review of experimental studies on risk perception, Epton et al., (2013) also reported that "messages that successfully heightened more than one of these elements of risk appraisal had larger effects on outcomes than messages that heightened only a single element."

The current theoretical development emphasizes a further distinction between the affective and the experiential elements of risk perception, as these two elements access and employ different information processing systems. The experiential component of risk perception has been described in the TriRisk model by Ferrer et al., (2016) as:

"rapid, heuristic-based judgments that involve " 'gut-level reactions' " and "as neither rule-based, logical assessments nor fully-fledged affective responses; they are outputs of experiential processing that is holistic, based on learned associations, slow to change, relatively crudely differentiated and integrated, and involving concrete images, metaphors, and narratives". These descriptions are based on previous conceptualization by other authors (Damasio, 1994; Sinclair et al., 2010; Windschitl, 2002; and Epstein et al., 1996). Ferrer and her colleagues (2016) do not provide a differential definition of their own. While the description might seem to lack clarity (Wilson et al., 2019), the operationalization of the experiential risk perception the TriRisk model (2016) is quite clear. It has been operationalized and measured as a 'gut-level perception of vulnerability to a given health risk' (Ferrer et al., 2018). They reported A) better model fit with the TriRisk model compared to single-factor or two-factor models; B) improved predictive validity, and C) important implications for targeting risk perception in health behavior change interventions. 


\section{How Do the Three Risk Processes Work?}

In addition to asking 'when', the second-generation research question (Zanna \& Fazio, 1982) also asks 'How'? How does the process work? "What mediates the effect?" The 'How' question is indeed an important one as it is likely to throw further light on how the three different risk perceptions work together to influence self-protective compliance behavior. More importantly, from the translational perspective, any evidence of such mediational effect is likely to have implications in framing communication messages for disease transmission reduction interventions.

Literature is rather sparse in this area. Some evidence was provided by Chapman \& Coups (2006), who reported that anticipated emotions, regret and worry, mediated the relationship between cognitive risk estimation and vaccination. Slovic et al. (2004) summarised some of the major empirical evidence to argue that the analytical processing of risk cannot be effective unless aided and guided by affect and emotion. They suggest a continuous interplay of the experiential, affective and deliberative processes in what they called "the dance of affect and reason" (Finucane et al., 2003), though they subsumed the affective and the experiential components in a single category, under the "two-mode thinking" conceptualization.

Support for the interplay between the deliberative processes and the experientialaffective processes comes from the neuroscience domain in the form of comparing hemodynamic activity in the brain. Mohr et al. (2010) based on their meta-analyses of 30 functional magnetic resonance imaging ( $\mathrm{fMRI}$ ) experiments, suggested that both the affective and the analytical risk-processing mechanisms work together in consort with one another. 


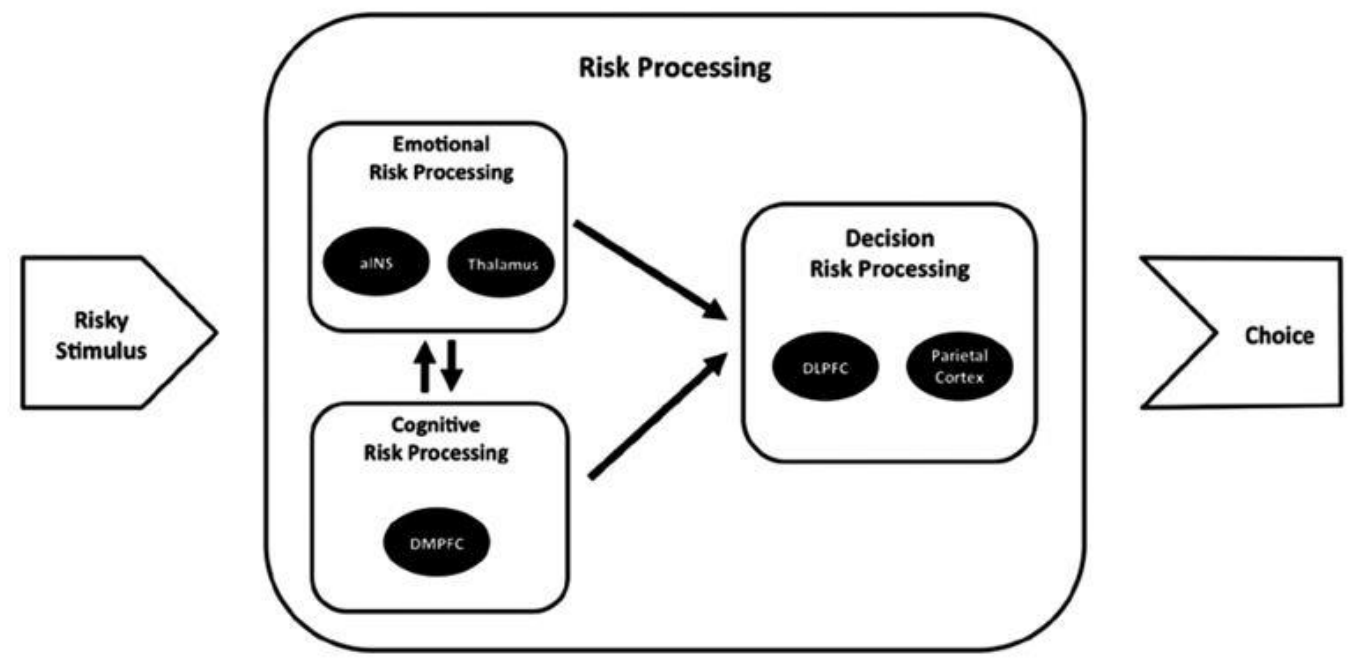

Figure 1: Risk Processing Mechanism proposed by Mohr et al., (2010).

(Reproduced with permission)

Exposure to a risky situation triggers both the cognitive and affective risk assessment processes. Throughout the sequence, the aINS and thalamus (executing the experientialaffective risk estimation) and the dmPFC (executing the cognitive-analytical path) keep talking to each other until the dorsolateral prefrontal cortex (dIPFC) integrates the risk information with other pertinent information to make an action decision. The results of the meta-analysis, authors note, are consistent with the essential postulates of the risk-as-feelings hypothesis (Loewenstein et al., 2001).Yet other investigations in the neurophysiological domain point to the direction of a stronger affect-to-cognitive path than the reverse path from cognitive to affect (LeDoux, 1996). But the most direct and unambiguous observation comes from Loewenstein who noted: " Diverse evidence also supports the proposition that affect mediates, at least in part, the relationship between an individual's cognitive evaluation of risk and his or her behavioral response to it." (Loewenstein, 2001). In one of the clearest review of conceptualization and research in this area, Kiviniemi et al., (2018) point out the limiting 
nature of the large body of mainstream research that treats affect and cognition as two isolated groups and attempts to investigate their effects on health behaviors as separately transmitted main effects, ignoring the complex interplay between them.

\section{Fatalism}

"My first encounter with fatalism in practice took place thirty years back when a maidservant who was absent for a week said on her return that her two-year-old son had died of smallpox. When I asked her whether he had been vaccinated against it she said in a piously resigned tone that since the boy was 'fated' to die of smallpox no vaccination would have prevented his death. Of course, this attitude is born of ignorance, but what shocked me was her acceptance of the death and the peace and consolation she derived from this acceptance." (Bhattacharji, 1982).

Another theoretical framework that has been the subject of considerable research in relation to health behaviors is Fatalism. Bhattacharji (1982) in her comprehensive treatise, described fatalism essentially as an "emphasis on the incalculable above the predictable" and analysed its interconnected facets that included, among others, predetermination, acceptance of one's situation, a coping mechanism, and "revolt against intellectualism, especially where rationality or intellectualism fails to solve certain problems". Other authors have defined fatalism variously, depending on their conceptualization and operationalization perspective, that inter alia includes elements of predetermination (Ross \& Ross, 1983), external locus of control (Wheaton, 1983), acceptance of one's situation (Futa et al., 2006), lack of personal control over destiny (Drew \& Schoenberg, 2011), and inevitability of unfortunate events (Nguesta and Kouabenan, 2017) .

The divergence in the operationalisation of fatalism has been reflected in the approach to its measurement. Esparza (2005) reported the existence of 51 different 
purported scales of fatalism with little convergence in their operational definitions. To integrate the different dimensions of fatalism, Esparza et al., (2015) developed a multidimensional fatalism scale that captured the different dimensions of fatalism under 5 subscales: fatalism, helplessness, internality, luck, and divine control. According to the authors, the first subscale - fatalism - embodies the core of the fatalism construct and should be the primary target of fatalism research. This subscale measures the "tendency to view all events as fixed in advance and inevitable", which closely approximates the idea of fatalism as it has existed in the traditional Indian belief system. Bhattacharji (1982) expressed the idea eloquently with the oft-repeated Sanskrit saying: "Niyatih Kena bāddhyate. which means "fate is incontrovertible - ... acquiescence to Fate Supreme."

Fatalism has been studied from diverse perspectives including, anthropological, sociological, and psychological perspectives. Within the health behavior research domain, the role of fatalism vis-à-vis health behaviors have been considered mainly from two explanatory standpoints. The first involves control beliefs and is related to the constructs of locus of control (Rotter, 1966), and self-efficacy belief (Bandura, 1986). Authors such as Straughan, (1998), proposed that fatalism influences self-efficacy, which in turn affects health behavior. They also argued that the social cognitive theory (Bandura, 1986) provided a more useful model for studying health behavior than rational choice models. The second standpoint, advanced by authors like Powe, (1997, 2001), Lange \& Piette (2006), have treated fatalism as a potential barrier to health behavior that needs to be modified for health behavior change interventions. Looked at from either standpoint, fatalism appears to be a useful construct to investigate together with $\mathrm{HBM}$ in attempts to predict self-protective health behavior. It is becoming increasingly more common for researchers to integrate constructs from different theoretical models in investigations involving HBM (Skinner et al., 2015). 


\section{The present study}

While both the HBM, and to a somewhat lesser degree, the construct of fatalism have been tested and applied in a wide range of diseases and health issues, the Covid-19 disease presents a very different set of dynamics, unlike anything hitherto known or seen. A disease, where the recommended health behaviors limit lives and livelihoods of people en masse by requiring extensive social isolation with its inevitable economic and emotional fallouts. This vastly different dynamics of the Covid-19 disease makes it imperative to examine afresh the applicability of a model like HBM that has been applied in a wide variety of other health issues. Thus, the present study:

1. Has a predominantly translational focus: to examine the applicability / transferability of the constructs of the HBM, the TriRisk model (Ferrer et al., 2016), and fatalismbelief in the context of the COVID-19 disease, specifically to test if they help us predict lockdown compliance behavior.

2. We also bring together the constructs of the HBM, TriRisk model, and fatalism under the same investigative umbrella for the first time, to the best of our knowledge.

3. Furthermore, we examine through mediation analysis how the three components of the TriRisk model work together, again for the first time, to the best of our knowledge.

With the translational goal in mind, we have consciously desisted from constructing elaborately formal hypotheses and making narrowly formulated a priori predictions, replacing them with testing expectations in relatively broader general directions, which are listed below:

We expect the basic components of HBM, the TriRisk model and fatalism to apply in the context of the -19 disease. Specifically, and additionally: 
1. All three risk components, viz., deliberative, affective, and experiential to be positively associated with and predict compliance behavior.

2. Benefits to be positively associated and barriers negatively, with compliance behavior.

3. Fatalism to be negatively associated with compliance behavior.

4. Finally, we intend to examine the interplay among the three risk perception components in the light of existing theoretical directions and available evidence.

\section{Methods and materials}

\section{Participants}

357 Participants from different parts of India responded to an invitation circulated through different online platforms that included social networking media and communication channels, such as LinkedIn, Facebook, Twitter, WhatsApp, email, etc., to participate in an online survey using the online google platform. The age range of participants were 15- 78 years $(M=47.64, S D=14.46), 41.5 \%$ of whom were men and $58.5 \%$ were women. Approximately $39 \%$ of the participants were from containment zones (hotspots) and $61 \%$ were from non-containment zones. The data were collected during May and June 2020, the complete lockdown phase in India. The demographic details of the participants $(N=357)$ are provided in the Appendix.

\section{Measures}

Both multi-item and single-item scales were used in the present study. Though multi-item scales are generally preferred, we wanted to reduce the burden on respondents as much as possible, as the study was conducted during the complete nation-wide lockdowns when peoples' lives were in a state of complete economic and psychological topsy-turvy. Hence, we decided to use single-item scales wherever possible. Use of single-item scales has been found to be justified on grounds of practicality, reduced burden, cost, and ease of interpretation 
(Bowling, 2005). Weinstein et al., (2007) specifically investigated the ability of several types of risk perception measures and of other constructs from health behavior theories to predict self-protective compliance behavior. They also compared single-item and multi-item scales to investigate their relative performance. Their conclusion was: "In this domain, a well-chosen single item scale can predict just as well as multi-item scale" (Weinstein et al., 2007). Singleitem scales in this area have been used by other researchers e.g., Ferrer et al., (2018), as well. The scales used are described below. A full list of the items has been provided in the Appendix.

1. Deliberative risk perception: Diefenbach et al., (1993) and Weinstein et al., (2007) reported that the 7-point scale performed best in assessing risk magnitude when compared to dichotomous item, percentage item and 6-point forced-choice item scales Based on this evidence, a single item 7-point scale was used that required participants to estimate the degree of risk probability by choosing from options that ranged from "almost zero" (=1) to "almost certain" (=7).

2. Experiential risk perception: Experiential risk perception measured the 'gut-level feeling of being at risk', assessed by a single-item 5-point scale.

Affective risk perception: Affective risk perception measured the elements of anxiety, fear (of putting family members at risk), and anticipated regret with a multi-item 5point scale. Item scores were added to generate a composite affective risk perception score. Cronbach's alpha is not an appropriate statistic in this case, as it is highly sensitive to the length of a scale. Mean inter-item correlation can give a better estimate of internal consistency and an optimal range from .20 to .40 has been suggested (Briggs \& Cheek, 1986). The mean inter-item correlation of the affective risk perception scale is 27 . 
3. Perceived severity: captured the perceived seriousness of the consequences (hospitalization, being put on ventilation, etc.) of contracting COVID-19. A single item scale with 5 response categories was used to assess perceived severity.

4. Perceived Barriers: This scale assessed the perceived obstacles (difficulty) in complying with the recommended preventive measures on a single-item 5-point scale.

5. Perceived Benefit: Participants responded to a single question on the effectiveness of the recommended lockdown and social distancing guidelines in preventing the COVID infection by choosing from options that ranged from "not at all effective" (=1) to "very effective" (=5).

6. Fatalism: The six-item 'Fatalism' scale, a subscale of the Multidimensional Fatalism Measure developed by O. A. Esparza et al., (2015), was used to measure the fatalism dimension. The authors describe this scale as measuring the "tendency to view all events as fixed in advance and inevitable". The scale has 6 items requiring a response on a 5-point "strongly disagree" (= 1) to "strongly agree" (=5) scale. The Cronbach alpha for the present study sample was found to be .89 .

7. Compliance behavior: is the dependent variable in the present study. It comprised 7 items that measured the extent to which respondents had been complying with the various lockdown-related preventive measures guidelines issued by the government, such as staying at home, social distancing, wearing masks in public, maintaining personal hygiene, etc. Response options for each item ranged from "Not at all" (=0) to "completely" (= 10). The composite compliance behavior score was derived by adding all the item scores. The Cronbach's alpha for the sample was .83. Factor analysis, using principal axis factoring yielded a single factor solution that explained $44.24 \%$ of the variance. 
8. Demographic variables: captured gender, age, education, income, and COVID hotspot status.

\section{Results and discussion}

The descriptive statistics and correlations between (a) components of the TriRisk model, perceived severity, benefits, barriers, and Fatalism; and (b) compliance behavior, are presented in Table 1.

Table1: Descriptive statistics and zero-order correlations between (a) components of the TriRisk model, perceived severity, benefits, barriers, and Fatalism; and (b) compliance behavior.

\begin{tabular}{llllllllll}
\hline Variables & Mean & $S D$ & 1 & 2 & 3 & 4 & 5 & 6 & 7
\end{tabular}

\begin{tabular}{lllllllllll}
\hline 1.Compliance & 60.78 & 9.41 & -- & $.21^{* *}$ & $.41^{* *}$ & $.24^{* *}$ & .08 & $.15^{* *}$ & $-.28^{* *}$ & $-.10^{*}$
\end{tabular}

\section{Behavior}

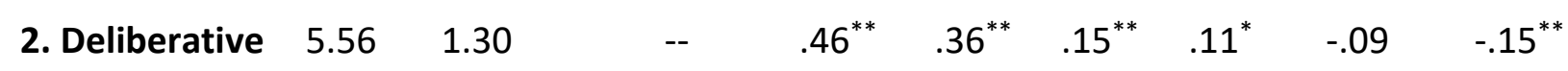

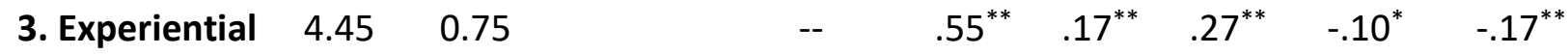

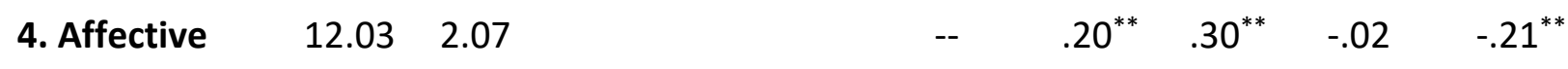

$\begin{array}{lllllllll}\text { 5. Severity } & 2.67 & 1.33 & -- & .05 & -.05 & -17^{* *}\end{array}$

$\begin{array}{lllllll}\text { 6. Benefit } & 4.14 & 0.84 & -- & -.07 & -.19^{* *}\end{array}$

$\begin{array}{lllll}\text { 7. } & \text { Barrier } 2.87 & 1.07 & -- & .13^{*}\end{array}$

8. Fatalism $\quad 16.25 \quad 5.49$

Note: ${ }^{*} p<.01$ and $* p<.05$

The correlations show that the risk perceptions, HBM components, and fatalism are associated with preventive health behavior, as expected. All the three dimensions of TRIRISK 
model are positively and significantly associated with compliance behavior with experiential risk perception having the strongest association, followed by affective, and deliberative. Perceived benefit too is significantly and positively correlated to compliance behavior while perceived barriers is significantly and negatively associated with compliance behavior, as expected. Very small relationship was observed between perceived severity and compliance behavior - an observation that has been consistently reported in the literature (Harrison et al., 1992; Carpenter, 2010). Fatalism was found to be significantly and negatively associated with compliance behavior, as expected. Overall, the patterns of associations between these predictors and health behavior appear to hold good for the COVID-19 pandemic.

Predicting Compliance from TriRisk Model, HBM and Fatalism

The results (significant predictors) are presented in the following tables:

Table 2: Multiple regression analyses predicting compliance behavior from different predictors

\begin{tabular}{|c|c|c|c|c|c|}
\hline \multirow[t]{3}{*}{ Model } & \multicolumn{2}{|c|}{ Unstandardized } & \multirow{2}{*}{$\begin{array}{l}\text { Standardized } \\
\text { Coefficients }\end{array}$} & \multirow[t]{3}{*}{$\mathrm{T}$} & \multirow[t]{3}{*}{ Sig. } \\
\hline & Coefficients & & & & \\
\hline & B & SE (HC4) & Beta & & \\
\hline (Constant) & 41.67 & 4.55 & & 9.16 & .00 \\
\hline Experiential & 4.02 & .76 & .32 & 5.31 & .00 \\
\hline Barrier & -1.98 & .42 & -.23 & 4.74 & .00 \\
\hline Gender & -2.87 & .94 & .15 & 3.06 & .00 \\
\hline
\end{tabular}

Note: Dependent Variable: Compliance behavior; Gender (Women = 0, Men =1) $\mathrm{R}^{2}=.274$ and Adjusted $\mathrm{R}^{2}=.242$

Only three variables, experiential risk perception, perceived barriers, and gender significantly predicted compliance behavior (Table 2). Together, they accounted for some $24 \%$ of the total variance. Experiential risk perception was the strongest predictor, followed by barriers, and gender. When the variables were entered in hierarchical models, experiential 
risk accounted for $17 \%$ of the variance. Incorporation of barriers in the equation explained another additional 5\%, and finally, introduction of gender in the model explained a further $2 \%$ of the variance.

The fact that deliberative risk perception did not turn out to be a significant predictor of compliance behavior is consistent with Carpenter's (2010) findings, who in his metaanalysis reported that "susceptibility was a weak predictor of behavior". That experiential risk perception would predict preventive health behavior was expected and is consistent with evidence available from several studies (Weinstein et al., 2007; Ferrer \& Klein, 2015; Ferrer et al., 2016; Ferrer et al., 2018). However, the elements of affective risk perception, viz., anxiety, fear and anticipated regret that have been previously found to be predictors of selfprotective behavior and or intentions (Chapman \& Coups, 2006; Weinstein et al., 2007; Ferrer et al., 2016; Ferrer et al., 2018) did not turn out to be so in the present study. Any discussion about the reason for this divergent finding would be speculative until we know more about the psychological dynamics of the COVID-19 disease.

Though benefits had a statistically significant association $(p<.01)$ with compliance behavior, the effect size was rather small - a finding that is somewhat unexpected as the literature indicates a stronger association (Carpenter, 2010). Also, we did not find benefits to be a significant predictor of compliance behavior. Again, at the cost of being speculative, it appears that the link between perceived benefits and compliance behavior could be somewhat tenuous during those early phases when the prevention guidelines were received possibly with incredulity, yet uncritically (the scepticism and the denial would come later); and compliance was to an extent externally enforced.

Barriers have consistently been found to be one of the strongest predictors of both behavior and intention (Rosenstock, 1974; Janz \& Becker, 1984; Carpenter, 2010). Though 
barriers in the context of COVID-19 presented health behavior challenges of a rather unique kind - social isolation - it was found to be a significant predictor of compliance behavior in the present study, as expected. Gender too was found to successfully predict compliance behavior, wherein women were associated with a significant increase in compliance behavior, compared to men.

Besides experiential risk perception, barriers, and gender, the only other variable that accounted for some additional variance was income. Better health compliance has been shown to be associated with higher income levels in many studies (Habib \& Durrani, 2018; Mukherjee et al., 2013). Our results, however, indicate that the relationship may not be as straightforward as it might otherwise seem. Only two income categories (₹ 60,000 to ₹ 100,$000 ;$ and > ₹ 150,000 per month) significantly predicted an increase in the compliance behavior, while the middle category ( $₹ 100,000$ to $₹ 150,000$ ) was not a statistically significant predictor.

Fatalism as a construct has been gaining currency and popularity in the last fifty years or so, and has been the subject of a large body of research involving health behavior. Fatalism has been implicated in failure to adopt self-protective behaviors in a wide variety of healthrelated areas (De Los Monteros \& Gallo, 2011; Shen et al., 2009). Cohn \& Esparza (2015) reported that $65 \%$ percent of the 46 studies, included in their meta-analysis found "at least one significant relationship in the predicted direction between fatalism and health behavior.". Kishore et al., (2008) reported that in a sample of Indian cancer patients that comprised semiskilled and skilled workers with no formal education, the majority held some form of fatalistic belief about cancer and its treatment; and that the average time to seek treatment after the disease had been first suspected, was 2 years. Several researchers, (e.g., Powe, 1997, 2001; 
Unger et al. (2002); Lange \& Piette, 2006), have suggested that to successfully modify health behaviors, fatalism related beliefs need to be considered.

However, in the present study, though there was a statistically significant negative relationship between fatalism and compliance behavior, fatalism was a weak and nonsignificant predictor of compliance. In a recent meta-analytic study of fatalism and health behavior, Cohn and Esparza (2015) reported that the average effect size was small $(d=0.26)$ equivalent to a point-biserial correlation of approximately 0.13 . They concluded that the relationship between fatalism and health behavior is possibly much smaller than previously thought or expected.

\section{Mediation Analysis}

Kiviniemi et al., (2018) recommended that in the interest of building more realistic models researchers routinely investigate mediating and moderating effects even if such investigations are done post hoc and were not a part of a priori expectations. In addition to multiple linear regression analyses and hierarchical regression models, we conducted exploratory mediation analyses to examine if our data revealed a similar mediational pattern as could be expected from the literature.

To test the mediational interplay of the risk processes, we built three separate parallel mediation models $(N=357)$, using ordinary least square path analysis. In each of the three models, all the predictor variables other than the ones in that model were controlled by entering them as covariates. $\mathrm{X}$ by $\mathrm{M}$ interactions were included in the equations to test the no-interaction assumption. In line with the current theory and practice (Hayes \& Rockwood, 2017; Hayes, 2017; Rucker et al., 2011), the estimation of indirect effects and bootstrap confidence intervals, based on 5,000 bootstrap samples, were used to test the mediation effects. All analyses were conducted using SPSS macro, PROCESS, version 3.5. To ensure 
heteroskedasticity-robust inference testing, we applied HC4 (Cribari-Neto) heteroskedasticity-consistent standard error estimator for OLS regressions in our regression analyses.

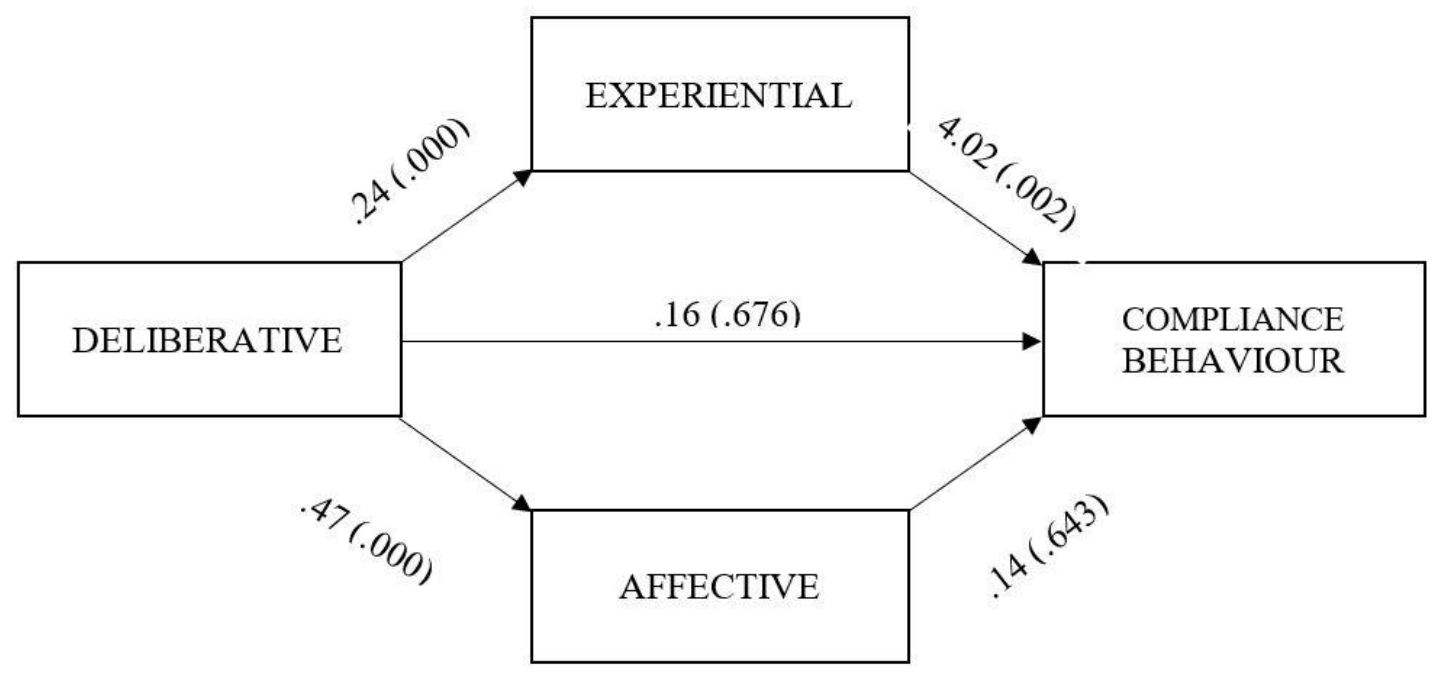

Figure 2: Parallel Mediation Model 1

Note: Showing unstandardized coefficients and observed significance levels

In the first model (Figure 2), the total effect of deliberative component on Compliance behavior was positive and significant ( $c=1.17, p=.009)$. However, the direct effect was not statistically significant $\left(c^{\prime}=0.16, p=.676\right)$. The first indirect effect between deliberative risk perception and Compliance behavior, mediated through experiential risk perception $\mathrm{M}_{1}\left(a_{1} b_{1}\right.$ $=0.94$ ) while controlling for affective risk perception $\mathrm{M}_{2}$, was entirely above zero, $95 \% \mathrm{Cl}$ (0.357 to 1.628). However, the second mediating variable $M_{2}$ mediated an indirect effect between deliberative risk perception and Compliance behavior that was $(a 2 b 2=0.07)$ nonsignificant, $95 \% \mathrm{Cl}(-0.195$ to 0.372$)$. Results of $X$ by $M$ interaction tests: $M_{1} * X, F^{H C 4}(1,339)=$ $0.01, p=.919$ and $\mathrm{M}_{2} * \mathrm{X}, \mathrm{F}^{\mathrm{HC} 4}(1,339)=0.12, p=.730$, support the assumption of no interaction between $\mathrm{X}$ and either mediator in this parallel mediator model. 


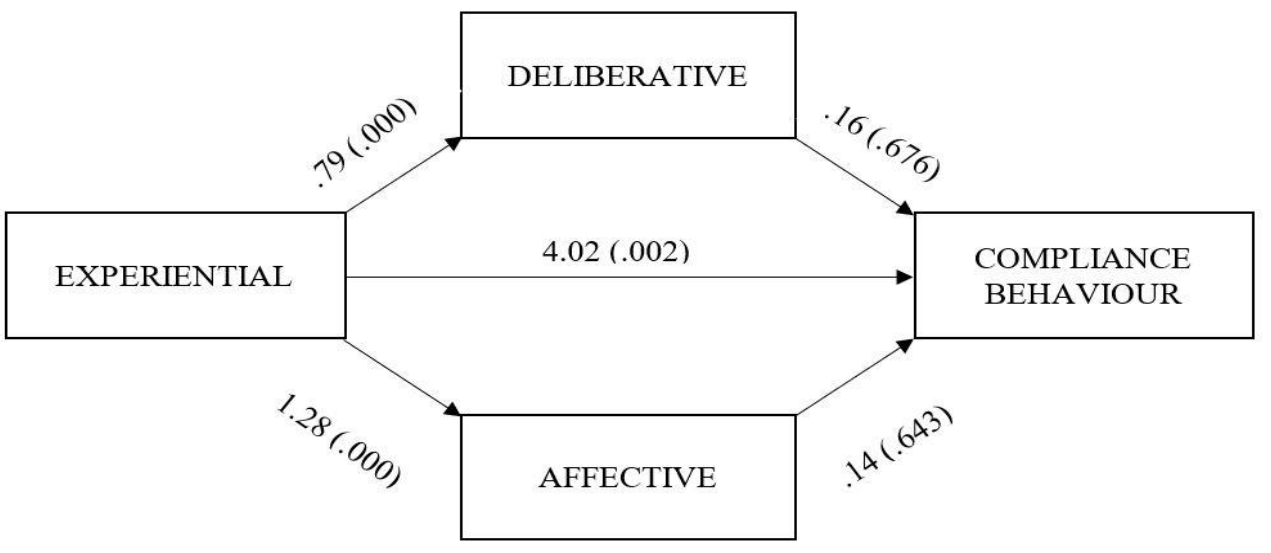

Figure 3: Parallel Mediation Model 2

Note: Showing unstandardized coefficients and observed significance levels

In the second model (Figure 3), almost the entire total effect of experiential risk perception on Compliance behavior $(c=4.33, p=.000)$, was direct effect $\left(c^{\prime}=4.02, p=.002\right)$. There was no evidence of indirect mediation through deliberative risk perception $\mathrm{M}_{1}\left(a_{1} b_{1}=\right.$ 0.13 , bootstrap $95 \% \mathrm{Cl}:-0.417,0.765)$ or through affective risk perception $\mathrm{M}_{2}\left(a_{2} b_{2}=0.18\right.$, bootstrap $95 \% \mathrm{Cl}:-0.506,1.015)$. Results of $\mathrm{X}$ by $\mathrm{M}$ interaction tests: $\mathrm{M}_{1}{ }^{*} \mathrm{X}$, remaining the same as reported in the previous model, and $\mathrm{M}_{2} * \mathrm{X}, \mathrm{F}^{\mathrm{HC} 4}(1,339)=0.11, p=.741$, support the assumption of no interaction between $\mathrm{X}$ and either mediator in this parallel mediator model.

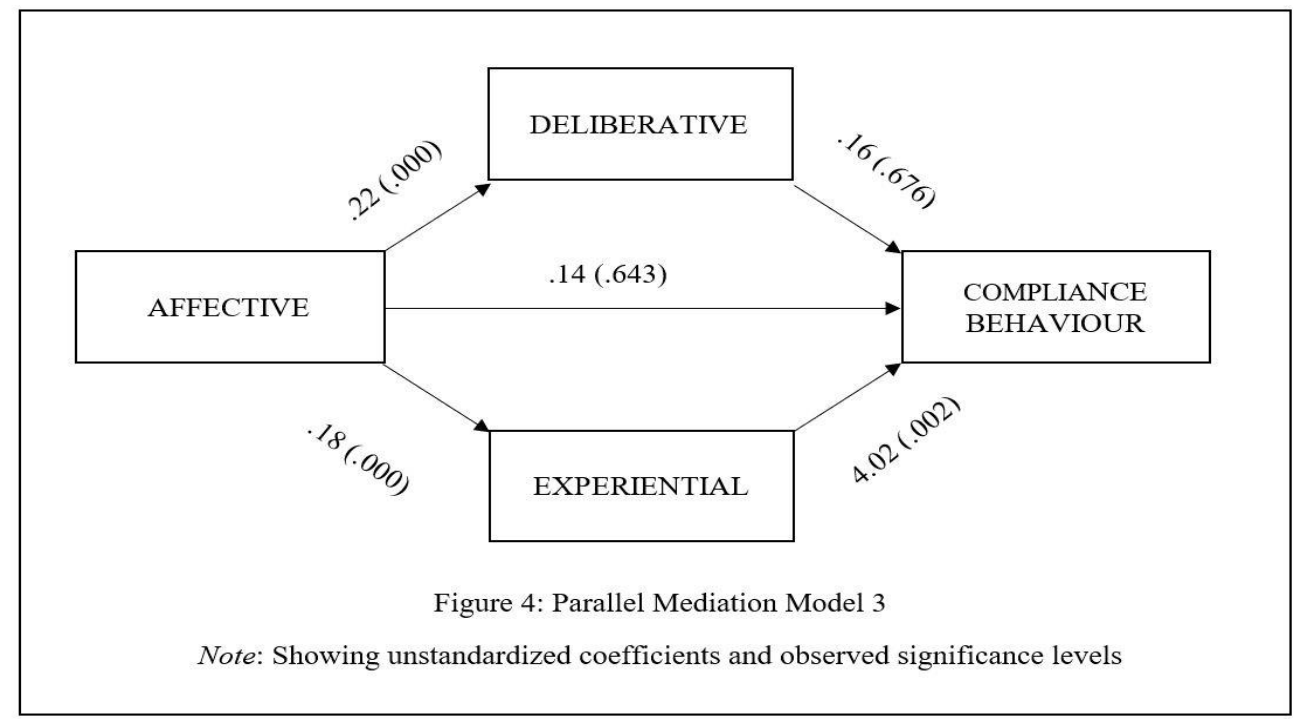


Finally, in the third model (Figure 4), we regressed Compliance behavior on the remaining non-analytical risk perception variable, viz., affective risk perception, and entered deliberative and experiential risk perceptions as proposed mediating variables, $M_{1}$ and $M_{2}$, respectively. While the total effect of affective risk perception on compliance behavior was positive and statistically significant $(c=0.90, p=.001)$, it was not through direct effect, which was non-significant $\left(c^{\prime}=0.14, p=.643\right)$. Again, there was no evidence of deliberative risk perception, $\mathrm{M}_{1}$, mediating the relationship between affective risk perception and compliance behavior $\left(a_{1} b_{1}=0.04\right.$, bootstrap $\left.95 \% \mathrm{Cl}:-0.120,0.230\right)$. That experiential risk perception, $\mathrm{M}_{2}$, mediated the association between affective risk perception and compliance behavior was established through the indirect effect $\left(a_{2} b_{2}=0.72,95 \%\right.$ bootstrap $\left.\mathrm{Cl}: 0.285,1.126\right)$.

The finding that experiential risk evaluation mediated the association between deliberative risk evaluation and Compliance behavior is consistent with the causal flow suggested by Loewenstein (2001).

However, the finding that the affective component in the present study that measured both experienced (anxiety, fear) and anticipated (regret) elements of the non-cognitive risk evaluation path did not similarly mediate cognitive risk evaluation, which was putatively expected, merits further investigation in future research.

\section{Limitations}

The primary limitation of this study involves the representational aspect of the sample. The data were collected from a convenience sample drawn, using Internet-based channels. In the absence of probability sampling generalisability remains an issue. However, generalisability, as a blanket requirement has been brought into question by several authors who essentially have asserted that representativeness of samples used need not be a necessary requirement 
if testing predictions rather than making them is the objective, (Mook, 1983), and that population inference is often not the objective of a study (Hayes, 2017). The same logic applies to the present study.

Another limitation related to the previous one is that the sample included only those respondents who have access to the Internet and can read English. Though English is one of the two national level official language in India and the second-most widely spoken second language in India after Hindi (Indian National Census Survey, 2011), its use is linked with education and income levels (Annamalai, 2004). Thus, those from the lower socioeconomic strata, and those who cannot read English, did not get included in the sample. Using verbal response scales in Hindi or other regional languages in future research would help overcome this limitation, which was not possible during a nation-wide lockdown when the data for the present study were collected.

\section{Concluding Remarks}

The essential findings of the present study are:

1. There were only three variables, amongst those we studied, that statistically significantly predicted COVID-related compliance behavior. experiential risk perception, perceived barriers, and gender.

2. Out of these, experiential risk perception was the strongest; it accounted for $17 \%$ of the variance in compliance behavior, followed by perceived barrier which explained another $5 \%$ variance. Gender accounted for about $2 \%$ of the total variance.

3. Though deliberative risk perception, 'susceptibility' in HBM, and affective risk perception both significantly and positively correlated with compliance behavior, neither of these two turned out to be statistically significant predictors of compliance behavior. 
4. Evidence suggested that experiential risk perception mediated the path between cognitive risk assessment and compliance behavior, not vice versa.

If the present study roughly corresponds to a stage somewhere between T0 and T1 in the translational research framework, point numbers 1 through 3 above, have implications for designing and trying out compliance enhancement interventions in the next stage. Use of appropriate experiential risk content in designing public campaigns and advisories is a strategy that merits further attention. No doubt, the hardest of barriers is economic in nature and structural support from governments by way of economic packages and other similar measures are needed to tide over the life versus livelihood conundrum. However, Reduction of perceived barriers through reassurances, dispelling misinformation, and providing assistance (Skinner et al, 2015) will potentially supplement the structural support.

Our findings - that experiential risk perception mediated the cognitive risk path to compliance - (point number 4), helps in understanding the nature of interplay between gut level sensing of risk and analytical risk assessment, vis-à-vis self-protective behavior. Loewenstein et al., (2001) noted that "...these rapid emotional reactions serve as a mechanism to interrupt and redirect cognitive processing toward potentially high-priority concerns, such as imminent sources of danger." Considering the fact that threat from infectious diseases has had a long history and has played a role in human evolution for more than 5 million years (Rumyantsev, 2012), it stands to reason that a deadly pandemic like COVID could activate what LeDoux ( J. LeDoux, 2012; J. E. LeDoux, 2014) called the "survival circuit". A process that kicks in, when significant challenges or opportunities in the environment are detected, and initiate actions to help self-preservation. The practical implication of our finding again points towards an increased importance that experiential risk 
perception merits in designing campaigns to promote social distancing and related preventive measures.

\section{References}

Abraham, C., \& Sheeran, P. (2005). The health belief model. Predicting health behavior, 2, 28-80.

Ajzen, I. and Fishbein, M. (1980) Understanding Attitudes and Predicting Social Behavior. Prentice-Hall, Englewood Cliffs.

Ajzen, I., \& Fishbein, M. (2000). Attitudes and the Attitude-Behavior Relation: Reasoned and Automatic Processes. European Review of Social Psychology, 11(1), 1-33.

Ajzen, I., \& Madden, T. J. (1986). Prediction of goal-directed behavior: Attitudes, intentions, and perceived behavioral control. Journal of Experimental Social Psychology, 22(5), 453474.

Annamalai, E. (2004). Nativization of English in India and its effect on multilingualism. Journal of Language and Politics, 3(1), 151-162.

Bandura, A. (1986). Fearful Expectations and Avoidant Actions as Coeffects of Perceived Self-Inefficacy. American Psychologist, 41(12), 1389-1391.

Becker, G. S. (1974). A Theory of Social Interactions. Journal of Political Economy, 82(6), 1063-1093. https://doi.org/10.1086/260265

Bhattacharji, S. (1982). Fatalism-Its roots and effects. Journal of Indian Philosophy, 10(2), 135-154.

Biddle, S. J., \& Nigg, C. R. (2000). Theories of exercise behavior. International Journal of Sport Psychology, 31(2), 290-304.

Bowling, A. (2005). Mode of questionnaire administration can have serious effects on data quality. Journal of Public Health, 27(3), 281-291.

Brewer, N. T., Chapman, G. B., Gibbons, F. X., Gerrard, M., McCaul, K. D., \& Weinstein, N. D. (2007). Meta-analysis of the relationship between risk perception and health behavior: The example of vaccination. Health Psychology, 26(2), 136-145.

Briggs, S. R., \& Cheek, J. M. (1986). The role of factor analysis in the development and evaluation of personality scales. Journal of Personality, 54(1), 106-148. https://doi.org/10.1111/j.1467-6494.1986.tb00391.x 
Carpenter, C. J. (2010). A meta-analysis of the effectiveness of health belief model variables in predicting behavior. Health Communication, 25(8), 661-669.

https://doi.org/10.1080/10410236.2010.521906

Chapman, G. B., \& Coups, E. J. (2006). Emotions and preventive health behavior: Worry, regret, and influenza vaccination. Health Psychology, 25(1), 82-90. https://doi.org/10.1037/0278-6133.25.1.82

Cohn, L. D., \& Esparza del Villar, O. A. (2015). Fatalism and health behavior: A meta-analytic review. Ciudad Juárez, México: Universidad Autónoma de Ciudad Juárez. Recuperado de https://bit. Iy/2sAF5/w.

Damasio, A. R. (1994). Descartes' error: Emotion, rationality and the human brain

De Los Monteros, K. E., \& Gallo, L. C. (2011). The relevance of fatalism in the study of Latinas' cancer screening behavior: A systematic review of the literature. In International Journal of Behavioral Medicine (Vol. 18, Issue 4, pp. 310-318). Springer. https://doi.org/10.1007/s12529-010-9119-4

Diefenbach, M. A., Weinstein, N. D., \& O'reilly, J. (1993). Scales for assessing perceptions of health hazard susceptibility. Health Education Research, 8(2), 181-192. https://doi.org/10.1093/her/8.2.181

Drew, E. M., \& Schoenberg, N. E. (2011). Deconstructing Fatalism: Ethnographic Perspectives on Women's Decision Making about Cancer Prevention and Treatment. Medical Anthropology Quarterly, 25(2), 164-182. https://doi.org/10.1111/j.15481387.2010.01136.x

Edwards, W. (1961). Behavioral Decision Theory. Annual Review of Psychology, 12(1), 473498. https://doi.org/10.1146/annurev.ps.12.020161.002353

Epstein, S., Pacini, R., Denes-Raj, V., \& Heier, H. (1996). Individual Differences in IntuitiveExperiential and Analytical-Rational Thinking Styles. Journal of Personality and Social Psychology, 71(2), 390-405. https://doi.org/10.1037/0022-3514.71.2.390

Epton, T., Norman, P., Sheeran, P., Harris, P. R., Webb, T. L., Ciravegna, F., Brennan, A., Meier, P., Julious, S. A., Naughton, D., Petroczi, A., Dadzie, A. S., \& Kruger, J. (2013). A theory-based online health behavior intervention for new university students: Study protocol. BMC Public Health, 13(1), 107. https://doi.org/10.1186/1471-2458-13-107

Esparza, O. A. (2005). Factors derived from fatalism scales and their relationship to healthrelated variables. The University of Texas at EI Paso. 
Esparza, O. A., Wiebe, J. S., \& Quiñones, J. (2015). Simultaneous Development of a Multidimensional Fatalism Measure in English and Spanish. Current Psychology, 34(4), 597-612. https://doi.org/10.1007/s12144-014-9272-z

Ferrer, R. A., \& Klein, W. M. P. (2015). Risk perceptions and health behavior. In Current Opinion in Psychology (Vol. 5, pp. 85-89). Elsevier. https://doi.org/10.1016/j.copsyc.2015.03.012

Ferrer, R. A., Klein, W. M. P., Avishai, A., Jones, K., Villegas, M., \& Sheeran, P. (2018). When does risk perception predict protection motivation for health threats? A person-bysituation analysis. PLOS ONE, 13(3), e0191994. https://doi.org/10.1371/journal.pone.0191994

Ferrer, R. A., Klein, W. M. P., Persoskie, A., Avishai-Yitshak, A., \& Sheeran, P. (2016). The Tripartite Model of Risk Perception (TRIRISK): Distinguishing Deliberative, Affective, and Experiential Components of Perceived Risk. Annals of Behavioral Medicine, 50(5), 653663. https://doi.org/10.1007/s12160-016-9790-z

Finucane, M. L., Peters, E., \& Slavic, P. (2003). Judgment and Decision Making: The Dance of Affect and Reason. Emerging perspectives on judgment and decision research, 327.

Floyd, D. L., Prentice-Dunn, S., \& Rogers, R. W. (2000). A meta-analysis of research on protection motivation theory. Journal of Applied Social Psychology, 30(2), 407-429. https://doi.org/10.1111/j.1559-1816.2000.tb02323.x

Futa, K. T., Hsu, E., \& Hansen, D. J. (2006). Child Sexual Abuse in Asian American Families: An Examination of Cultural Factors That Influence Prevalence, Identification, and Treatment. Clinical Psychology: Science and Practice, 8(2), 189-209. https://doi.org/10.1093/clipsy.8.2.189

Gerrard, M., Gibbons, F. X., \& Bushman, B. J. (1996). Relation Between Perceived Vulnerability to HIV and Precautionary Sexual Behavior. In psycnet.apa.org (Vol. 119, Issue 3). Psychological Association, Inc. https://psycnet.apa.org/journals/bul/119/3/390.html?uid=1996-01402-004

Habib, F., \& Durrani, A. M. (2018). Impact of dietary pattern on glycemic level among type 2 diabetic patients. Current Research in Nutrition and Food Science, 6(1), 120-126. https://doi.org/10.12944/CRNFSJ.6.1.13 
Harrison, J. A., Mullen, P. D., \& Green, L. W. (1992). A meta-analysis of studies of the health belief model with adults. Health Education Research, 7(1), 107-116. https://doi.org/10.1093/her/7.1.107

Hayes, A. F. (2017). Introduction to mediation, moderation, and conditional process analysis: A regression-based approach. Guilford publications.

Hayes, A. F., \& Rockwood, N. J. (2017). Regression-based statistical mediation and moderation analysis in clinical research: Observations, recommendations, and implementation. Behavior Research and Therapy, 98, 39-57. https://doi.org/10.1016/j.brat.2016.11.001

Hochbaum, G. M. (1958). Public participation in medical screening programs: A sociopsychological study (No. 572). US Department of Health, Education, and Welfare, Public Health Service, Bureau of State Services, Division of Special Health Services, Tuberculosis Program.

Janz, N. K., \& Becker, M. H. (1984). The health belief model: A decade later. Health education quarterly, 11(1), 1-47.

Kishore, J., Ahmad, I., Kaur, R., \& Mohanta, P. K. (2008). Beliefs and perceptions about cancers among patients attending radiotherapy OPD in Delhi, India. Asian Pac J Cancer Prev, 9(1), 155-158.

Kiviniemi, M. T., Ellis, E. M., Hall, M. G., Moss, J. L., Lillie, S. E., Brewer, N. T., \& Klein, W. M. P. (2018). Mediation, moderation, and context: Understanding complex relations among cognition, affect, and health behavior. Psychology and Health, 33(1), 98-116. https://doi.org/10.1080/08870446.2017.1324973

Lange, L. J., \& Piette, J. D. (2006). Personal Models for Diabetes in Context and Patients' Health Status. Journal of Behavioral Medicine, 29(3). https://doi.org/10.1007/s10865-0069049-4

LeDoux, J. (1996). The emotional brain. New York: Simon \&amp; Schuster

LeDoux, J. (2012). Rethinking the Emotional Brain. In Neuron (Vol. 73, Issue 4, pp. 653-676). Cell Press. https://doi.org/10.1016/j.neuron.2012.02.004

LeDoux, J. E. (2014). Coming to terms with fear. In Proceedings of the National Academy of Sciences of the United States of America (Vol. 111, Issue 8, pp. 2871-2878). National Academy of Sciences. https://doi.org/10.1073/pnas.1400335111 
Liu, T., Hu, J., Kang, M., Lin, L., Zhong, H., Xiao, J., He, G., Song, T., Huang, Q., Rong, Z., Deng, A., Zeng, W., Tan, X., Zeng, S., Zhu, Z., Li, J., Wan, D., Lu, J., Deng, H., ... Ma, W. (2020). Transmission dynamics of 2019 novel coronavirus (2019-nCoV). BioRxiv.

Loewenstein, G. F., Hsee, C. K., Weber, E. U., \& Welch, N. (2001). Risk as Feelings.

Psychological Bulletin, 127(2), 267-286. https://doi.org/10.1037/0033-2909.127.2.267

Maddux, J. E., \& Rogers, R. W. (1983). Protection motivation and self-efficacy: A revised theory of fear appeals and attitude change. Journal of Experimental Social Psychology, 19(5), 469-479. https://doi.org/10.1016/0022-1031(83)90023-9

Mohr, H. M., Zimmermann, J., Röder, C., Lenz, C., Overbeck, G., \& Grabhorn, R. (2010). Separating two components of body image in anorexia nervosa using fMRI. Psychological medicine, 40(9), 1519.

Mook, D. G. (1983). In defense of external invalidity. American Psychologist, 38(4), 379-387. https://doi.org/10.1037/0003-066X.38.4.379

Mukherjee, S., Sarkar, B. S., Das, K. K., Bhattacharyya, A., \& Deb, A. (2013). Original articlecompliance to anti-diabetic drugs:Observations from the diabetic clinic of a medical college in Kolkata, India. Journal of Clinical and Diagnostic Research, 7(4), 661-665. https://doi.org/10.7860/JCDR/2013/5352.2876

Murray-Johnson, L., Witte, K., Boulay, M., Figueroa, M. E., Storey, D., \& Tweedie, I. (2005). Using Health Education Theories to Explain Behavior Change: A Cross-Country Analysis. International Quarterly of Community Health Education, 25(1), 185-207. https://doi.org/10.2190/1500-1461-44GK-M325

Ngueutsa, R., \& Kouabenan, D. R. (2017). Fatalistic beliefs, risk perception and traffic safe behaviors. European review of applied psychology, 67(6), 307-316.

Noar, S. M., \& Zimmerman, R. S. (2005). Health Behavior Theory and cumulative knowledge regarding health behaviors: Are we moving in the right direction? In Health Education Research (Vol. 20, Issue 3, pp. 275-290). Oxford Academic.

Powe, B. D. (1997). Cancer fatalism - Spiritual perspectives. In Journal of Religion and Health (Vol. 36, Issue 2, pp. 135-144). Kluwer Academic/Human Sciences Press Inc.

Powe, B. D. (2001). Cancer fatalism among elderly African American women: Predictors of the intensity of the perceptions. Journal of Psychosocial Oncology, 19(3-4), 85-95. 
Prochaska, J. O., \& DiClemente, C. C. (1983). Stages and processes of self-change of smoking: Toward an integrative model of change. Journal of Consulting and Clinical Psychology, 51(3), 390-395. https://doi.org/10.1037/0022-006X.51.3.390

Registrar general, I. (2011). CENSUS OF INDIA 2011.

Rosenstock, I. M. (1974). Historical Origins of the Health Belief Model. Health Education Monographs, 2(4), 328-335. https://doi.org/10.1177/109019817400200403

Ross, M. E., \& Ross, C. L. (1983). Mothers, Infants, and the Psychoanalytic Study of Ritual. Signs: Journal of Women in Culture and Society, 9(1), 26-39.

Rotter, J. B. (1966). Generalized expectancies for internal versus external control of reinforcement. In Psychological monographs (Vol. 80, Issue 1, pp. 1-28).

Rucker, D. D., Preacher, K. J., Tormala, Z. L., \& Petty, R. E. (2011). Mediation Analysis in Social Psychology: Current Practices and New Recommendations. Social and Personality Psychology Compass, 5(6), 359-371. https://doi.org/10.1111/j.1751-9004.2011.00355.x

Rumyantsev, S. (2012). Where and When Human Viral Epidemics First Emerged. British Journal of Medicine and Medical Research, 2(4), 647-661. https://doi.org/10.9734/bjmmr/2012/1692

Shen, L., Condit, C. M., \& Wright, L. (2009). The psychometric property and validation of a fatalism scale. Psychology and Health, 24(5), 597-613. https://doi.org/10.1080/08870440801902535

Sinclair, M., Ashkanasy, N. M., \& Chattopadhyay, P. (2010). Affective antecedents of intuitive decision making. Journal of Management and Organization, 16(3), 382-398. https://doi.org/10.5172/jmo.16.3.382

Skinner, C. S., Tiro, J., \& Champion, V. L. (2015). Background on the health belief model. Health behavior: Theory, research, and practice, 75 .

Slovic, P., Finucane, M. L., Peters, E., \& MacGregor, D. G. (2004). Risk as Analysis and Risk as Feelings: Some Thoughts about Affect, Reason, Risk, and Rationality. In Risk Analysis (Vol. 24, Issue 2, pp. 311-322). John Wiley \& Sons, Ltd. https://doi.org/10.1111/j.02724332.2004.00433.x

Slovic, P., Peters, E., Finucane, M. L., \& MacGregor, D. G. (2005). Affect, risk, and decision making. In Health Psychology (Vol. 24, Issue 4 SUPPL.). https://doi.org/10.1037/02786133.24.4.S35 
Straughan, P. T. (1998). Fatalism Reconceptualized: A Concept to Predict Health Screening Behavior. Journal of Gender, Culture, and Health, 3(2), 85-100. https://doi.org/10.1023/A:1023278230797

Unger, J. B., Ritt-Olson, A., Teran, L., Huang, T., Hoffman, B. R., \& Palmer, P. (2002). Cultural values and substance use in a multiethnic sample of California adolescents. Addiction Research \& Theory, 10(3), 257-279.

Weinstein, N. D., Kwitel, A., McCaul, K. D., Magnan, R. E., Gerrard, M., \& Gibbons, F. X. (2007). Risk perceptions: Assessment and relationship to influenza vaccination. Health Psychology, 26(2), 146-151. https://doi.org/10.1037/0278-6133.26.2.146

Wheaton, B. (1983). Stress, personal coping resources, and psychiatric symptoms: An investigation of interactive models. Journal of Health and Social Behavior, 24(3), 208-229. https://doi.org/10.2307/2136572

Wilson, R. S., Zwickle, A., \& Walpole, H. (2019). Developing a Broadly Applicable Measure of Risk Perception. Risk Analysis, 39(4), 777-791. https://doi.org/10.1111/risa.13207

Windschitl, M. (2002). Framing Constructivism in Practice as the Negotiation of Dilemmas: An Analysis of the Conceptual, Pedagogical, Cultural, and Political Challenges Facing Teachers. Review of Educational Research, 72(2), 131-175. https://doi.org/10.3102/00346543072002131

Witte, K. (1994). Fear control and danger control: A test of the extended parallel process model (EPPM). Communication Monographs, 61(2), 113-134. https://doi.org/10.1080/03637759409376328

Zanna, M. P., \& Fazio, R. H. (1982). The attitude-behavior relation: Moving toward a third generation of research. In Consistency in social behavior: The Ontario symposium (Vol. 2, pp. 283-301). 